\title{
EXPRESSION OF VASCULAR ENDOTHELIAL GROWTH FACTOR AND ANGIOGENESIS IN CARDIAC MYXOMA: A STUDY OF FIFTEEN PATIENTS
}

Tetsuya Kono, MD

Naohiko Koide, MD

Yoshiyuki Hama, MD

Hiroto Kitahara, MD

Hirohumi Nakano, $\mathrm{MD}^{\mathrm{a}}$

Jun-ichi Suzuki, MD ${ }^{\mathrm{b}}$

Mitsuaki Isobe, $\mathrm{MD}^{\mathrm{b}}$

Jun Amano, MD
Objective: To clarify the association between angiogenesis and the clinicopathologic features in cardiac myxoma, vascular endothelial growth factor expression in the myxoma was examined by using reverse transcriptase polymerase chain reaction and immunohistochemistry, and the microvessel density was determined by counting microvessels in the myxoma by using immunostaining for platelet endothelial cell adhesion molecule 1. Methods: Seven fresh-frozen and 15 formalin-embedded tissues were analyzed by means of reverse transcriptase polymerase chain reaction and immunostaining for vascular endothelial growth factor, respectively. The microvessel density was measured in the 15 formalinembedded tissues. Furthermore, immunostaining for proliferating cell nuclear antigen was performed, and the proliferating cell nuclear antigen-labeling index was calculated. Results: All of the 7 analyzed myxomas were positive for vascular endothelial growth factor messenger RNA, as determined by means of reverse transcriptase polymerase chain reaction, whereas atrial septum and atrium tissues were negative. Positive immunohistochemical reaction for vascular endothelial growth factor was observed in the cells of all 15 myxomas. The size of myxomas with high vascular endothelial growth factor expression was smaller than that of myxomas with low vascular endothelial growth factor expression. The microvessel density in myxomas with high vascular endothelial growth factor expression was higher than that in myxomas with low vascular endothelial growth factor expression. There was an inverse correlation between the tumor size and the ratio of the microvessel density in the central part to the microvessel density in the peripheral part of myxomas. Furthermore, there was an inverse correlation between the proliferating cell nuclear antigen-labeling index and the tumor size, and the prolferating cell nuclear antigen-labeling index in myxomas with high vascular endothelial growth factor expression was higher than that in myxomas with low vascular endothelial growth factor expression. Conclusions: Cardiac myxomas produce vascular endothelial growth factor, which probably induces angiogenesis for tumor growth. (J Thorac Cardiovasc Surg 2000;119:101-7)
C ardiac myxoma is an endocardial neoplasm that arises from multipotential mesenchymal cells. ${ }^{1}$ This tumor generally appears to grow rather quickly and causes hemodynamic derangement and embolic

From the Second Department of Surgerya and First Department of Internal Medicine, ${ }^{\mathrm{b}}$ Shinshu University School of Medicine, Matsumoto, Japan.

Supported in part by a grant from Japanese Ministry of Education, Science, Sports, and Culture (B-2, 09470246).

Received for publication April 1, 1999; revisions requested May 27, 1999; revisions received Sept 8, 1999; accepted for publication Sept 21, 1999. episodes in some patients. ${ }^{2}$ Angiogenesis plays an important role in tumor growth ${ }^{3}$ and is controlled and maintained by several kinds of angiogenic factors in many solid tumors. ${ }^{4}$ Vascular endothelial growth factor

\footnotetext{
Address for reprints: Naohiko Koide, MD, Second Department of Surgery, Shinshu University School of Medicine, Asahi, 3-1-1, Matsumoto 390-8621, Japan (E-mail: surgery 2@hsp.md.shinshu-u.ac.jp).

Copyright (@) 2000 by Mosby, Inc.

$0022-5223 / 2000 \$ 12.00+0 \quad \mathbf{1 2 / 1 / 1 0 3 1 4 2}$
} 
Table I. The clinicopathologic features of patients with cardiac myxoma

\begin{tabular}{|c|c|c|c|c|c|c|c|}
\hline $\begin{array}{l}\text { Patient } \\
\text { No. }\end{array}$ & $\begin{array}{l}\text { Age } \\
(y)\end{array}$ & Sex & Location & Symptom & $\begin{array}{l}\text { Size } \\
(\mathrm{mm})\end{array}$ & $\begin{array}{c}\text { Serum } C R P \\
(m g / d L)\end{array}$ & $\begin{array}{c}\text { Macroscopic } \\
\text { findings }\end{array}$ \\
\hline 1 & 45 & $\mathrm{~F}$ & LA & Cerebral embolism & 33 & 0.21 & Smooth \\
\hline 2 & 66 & $\mathrm{~F}$ & LA & Left hemiplegia & 55 & 2.51 & Smooth \\
\hline 3 & 51 & $\mathrm{~F}$ & LA & Palpitation, dyspnea & 60 & 2.37 & Myxoid \\
\hline 4 & 68 & $\mathrm{~F}$ & LA & PVC on ECG & 70 & 1.62 & Friable \\
\hline 5 & 61 & M & RA & SOB & 85 & 0.50 & Smooth \\
\hline 6 & 62 & $\mathrm{~F}$ & LA & SOB & 50 & 0.30 & Smooth \\
\hline 7 & 68 & $\mathrm{~F}$ & LA & DOE & 45 & 0.64 & Smooth \\
\hline 8 & 68 & $\mathrm{~F}$ & LA & DOE & 50 & 2.10 & Smooth \\
\hline 9 & 36 & $\mathrm{~F}$ & RA & DOE & 70 & 1.10 & Myxoid \\
\hline 10 & 70 & $\mathrm{~F}$ & LA & Palpitation & 50 & - & Myxoid \\
\hline 11 & 86 & M & LA & Left hemiplegia & 58 & 0.12 & Friable \\
\hline 12 & 70 & M & LA & SOB, cough & 60 & - & Myxoid \\
\hline 13 & 72 & $\mathrm{~F}$ & LA & Dermatomyositis & 34 & 0.72 & Myxoid \\
\hline 14 & 20 & M & LA & Chest pain & 80 & 2.80 & Myxoid \\
\hline 15 & 68 & M & LA & Cerebral infarction & 55 & - & Myxoid \\
\hline
\end{tabular}

$C R P$, C-reactive protein; $L A$, Left atrium; $R A$, right atrium; $P V C$, premature ventricular contraction; $E C G$, electrocardiography; $S O B$, shortness of breath; $D O E$, dyspnea on exertion.

(VEGF) is an angiogenic factor that stimulates growth of endothelial cells ${ }^{5,6}$ and is a major angiogenic factor in several solid tumors. ${ }^{6}$ In the stroma of cardiac myxoma, microvessels are frequently observed histologically, and angiography shows that tumor vessels are supplied from branches of the coronary arteries. ${ }^{7}$ However, angiogenesis in cardiac myxoma is not yet well understood.

In this study VEGF expression of cardiac myxoma was examined by using reverse transcriptase polymerase chain reaction (RT-PCR) and immunohistochemistry, microvessel density was determined by counting the microvessels in cardiac myxoma by using immunostaining for platelet endothelial cell adhesion molecule-1 (PECAM-1), ${ }^{8}$ and proliferating cell nuclear antigen (PCNA) immunostaining was performed to clarify the association between angiogenesis and the clinicopathologic features of cardiac myxoma.

\section{Methods}

Patients and tissue preparation. Tissue samples of cardiac myxoma were obtained from 15 patients who underwent cardiac surgery between 1988 and 1998 in the Second Department of Surgery, Shinshu University Hospital, and affilliated hospitals. The clinicopathologic features of the patients with cardiac myxoma are summarized in Table I. The tumor size was defined as the largest diameter of the tumor. Macroscopic findings were classified into 3 types: smooth type, myxoid type, and friable type. ${ }^{9}$ Fresh samples about $8 \times$ $8 \times 8 \mathrm{~mm}$ were collected from 7 of the 15 resected myxomas. The myxoma tissues were immersed in liquid nitrogen immediately after resection and then were stored frozen at $-80^{\circ} \mathrm{C}$. The resected myxomas taken from the 15 patients were fixed in $10 \%$ formalin buffered with phosphate at $\mathrm{pH} 7.4$ and embedded in paraffin. Serial sections were made and mounted on glass slides. Hematoxylin-eosin staining was performed to confirm the diagnosis of the tumors as myxoma.

RT-PCR for VEGF. Seven myxomas and 2 atrial septum and 2 atrium tissues (as controls) were investigated by using RT-PCR for VEGF. Total RNA was isolated as described by Chomczynski and Sacchi. ${ }^{10}$ For reverse transcription to complementary (c)DNA, $4 \mu \mathrm{g}$ of total RNA was used. RNA was denatured for 5 minutes at $99^{\circ} \mathrm{C}$ and then reverse transcribed by incubation for 15 minutes at $42^{\circ} \mathrm{C}$ in the presence of 25 $\mathrm{mmol} / \mathrm{L} \mathrm{MgCl}_{2} ; 10 \times$ PCR Buffer II; random hexamer; diethyl pyrocarbonate-treated, autoclaved, deionized, ultrafiltered water; RNase inhibitor; and murine leukemia virus reverse transcriptase (Perkin Elmer Cetus, Norwalk, Conn). PCR was performed with $3 \mu \mathrm{L}$ of cDNA in a final reaction volume of $15 \mu \mathrm{L}$. The assay mix contained diethyl pyrocarbonate-treated autoclaved, deionized, ultrafiltered water; $10 \times$ PCR Buffer II; $25 \mathrm{mmol} / \mathrm{L} \mathrm{MgCl}_{2} ; 10 \mathrm{pmol} / \mathrm{L}$ of the respective primers; and $2.5 \mathrm{U}$ of Taq DNA polymerase (Perkin Elmer Cetus). The VEGF primers were provided by $\mathrm{Dr} \mathrm{H}$. A. Weich (Braunschweig, Germany), and glyceraldehyde-phosphate dehydrogenase primers were obtained from JCRB (Tokyo, Japan). The conditions consisted of denaturation at $95^{\circ} \mathrm{C}$ for 10 minutes, 35 cycles of annealing at $94^{\circ} \mathrm{C}$ for 30 seconds, and extension at $60^{\circ} \mathrm{C}$ for 30 seconds. The PCR products were analyzed by means of electrophoresis on $5 \%$ polyacrylamide gels, stained with ethidium bromide, and photographed under UV light.

Immunostaining for VEGF. Fifteen myxomas and 2 atrial septum and 2 atrium tissues (as controls) were investigated by means of VEGF immunostaining. The avidin-biotin complex $(\mathrm{ABC})$ method was used for VEGF immunostaining. After deparaffinization with xylene, the sections were transferred to water through a graded series of ethanol and treated 


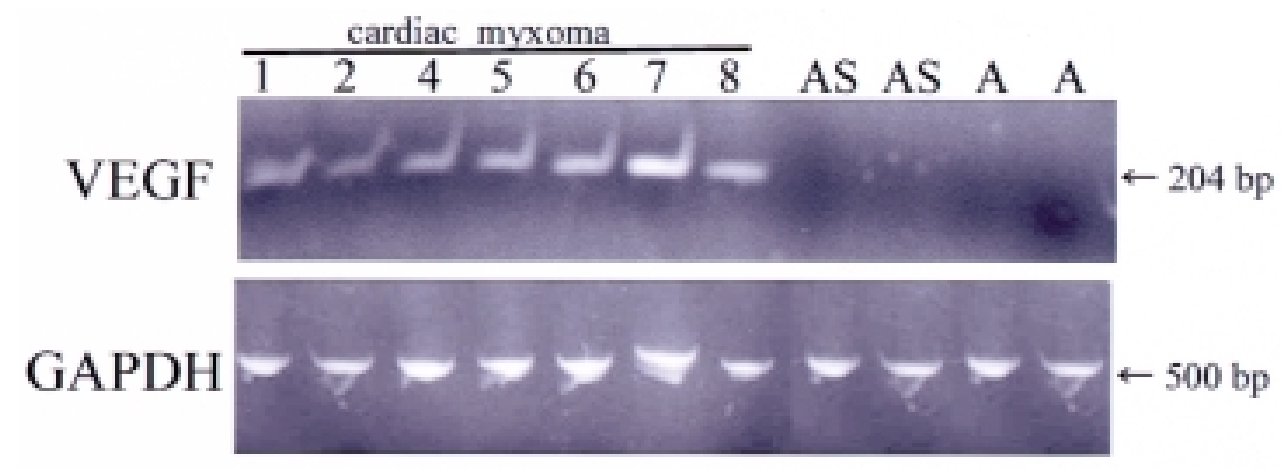

Fig 1. RT-PCR for VEGF of the 7 cardiac myxomas. Lanes 1 to 7 were positive for VEGF-mRNA; lanes $A$ and $A S$ were negative. Lanes 1-7, Patients 1, 2, 4, 5, 6, 7, and 8, respectively. AS, Atrial septum; A, atrium; GAPDH, glyceraldehyde-phosphate dehydrogenase.

as follows: incubation with $2 \%$ normal horse serum for 30 minutes, with mouse anti-human VEGF IgG monoclonal antibody (R11; Immuno-Biological Laboratories, Fujioka, Japan) diluted 250-fold for 120 minutes and horse biotinylated anti-mouse IgG antibodies (Vector Laboratories, Inc, Burlingame, Calif) diluted 200-fold for 60 minutes. Avidinbiotinylated peroxidase complex (Vector Laboratories) was used to treat the sections for 60 minutes. To dilute the antibodies, $20 \mathrm{mmol} / \mathrm{L}$ sodium phosphate containing $0.15 \mathrm{~mol} / \mathrm{L}$ sodium chloride at $\mathrm{pH} 7.4$ was used. After incubation in the antibody solutions, the sections were incubated in a solution of $0.05 \% 3,3^{\prime}$-diaminobenzidine tetrachloride (DAB) and $0.01 \%$ hydrogen peroxide in $50 \mathrm{mmol} / \mathrm{L}$ Tris-hydrochloric acid ( $\mathrm{pH}$ 7.2) for 10 minutes and then counterstained with $1 \%$ methyl green stain. Normal mouse IgG was used for the primary antibody as a negative control.

Staining results were scored from + to ++++ on the basis of the percentage of the myxoma cells showing positive staining for VEGF. Scores were based on the following scale: ++++ , over $86 \%$ of the myxoma cells showed positive staining; +++, $61 \%$ to $85 \%$ of the myxoma cells showed positive staining; ,$++ 31 \%$ to $60 \%$ of the myxoma cells showed positive staining; and,$+ 0 \%$ to $30 \%$ of the myxoma cells showed positive staining. The tumors were then classified into 2 groups; the high-VEGF expression group showed positive reactions of +++ or ++++ , and the low-VEGF expression group showed positive reactions of + or ++ .

Immunostaining for PECAM-1 and measurement of microvessel density. Immunostaining of PECAM-1 was performed by using the $\mathrm{ABC}$ method with monoclonal antibody JC70 (Dako Patts, Glostrup, Denmark), which recognizes PECAM-1, diluted 500-fold. Sections immersed in 10 $\mathrm{mmol} / \mathrm{L}$ citrate buffer were treated in a microwave oven before staining. The number of microvessels was counted according to the method of Maeda and colleagues. ${ }^{11}$ The PECAM-1-stained sections were screened at 5-fold magnification under a microscope to identify the areas of highest vascular density within the whole area of myxoma tissue. Microvessels in myxomas were counted in the 6 areas with the highest density at 200-fold magnification. Microvessel density in the whole area of myxoma tissue was then expressed as the average of the microvessel count in these areas. Furthermore, to investigate the distribution of the microvessels in myxomas, the cut surface of the tumor was divided into 2 areas; the peripheral part was defined as an outside quarter, and the central part was defined as the remaining part. Microvessel density in the central part of the myxoma tissue and microvessel density in the peripheral part were measured by the same procedure used for microvessel density in the whole area in each respective portion. Then the ratio of the microvessel density in the central part to the microvessel density in the peripheral part was calculated.

PCNA immunostaining and measurement of PCNAlabeling index. Immunostaining of PCNA was performed by using the $\mathrm{ABC}$ method with monoclonal antibody PC10 (Dako Patts) diluted 100-fold. Serial sections adjacent to those stained for VEGF were immunostained for PCNA. Among the uniformly stained fields, 6 or 7 photomicrographs were randomly taken from each section for quantifying the number of PCNA-positive nuclei. Seventy or 80 myxoma cells were counted in each photograph, and about 500 cells from each specimen were thus evaluated. A dark accumulation of DAB in the nuclei was judged to indicate a positive reaction. The rate of PCNA-positive nuclei was calculated for each section on the basis of about 500 myxoma cells (PCNAlabeling index). The judgement of PCNA-positive nuclei could be made in most cases but was difficult in some myxoma cells of a few patients. When there were no apparent differences with regard to the staining intensity between the nucleus and cytoplasm, the myxoma cells were judged to be negative.

Statistical analysis. The clinicopathologic features and histochemical results were analyzed by using the MannWhitney test or the $\chi^{2}$ test. The Pearson correlation coefficient was determined for the analysis of the relationship between tumor size and microvessel density and between microvessel density and PCNA-labeling index. 

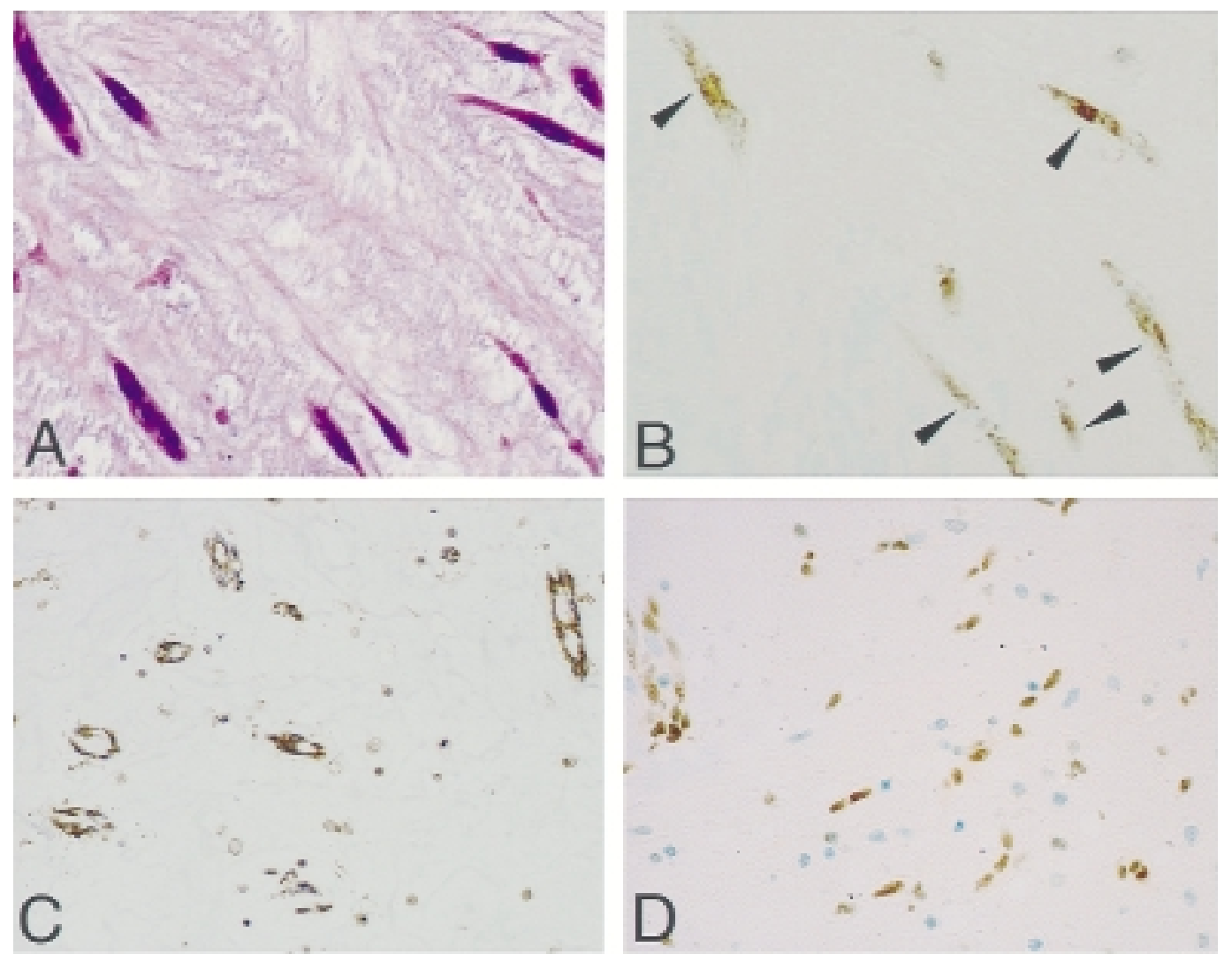

Fig 2. Immunostaining of VEGF, PECAM-1 and PCNA. A, Hematoxylin-eosin staining and B, VEGF staining: a positive immunoreaction for VEGF was observed as a dark accumulation of DAB reaction products in the cytoplasm of the tumor cells (arrows). This tumor was scored ++++. C, PECAM-1 staining. A positive reaction for PECAM-1 was observed as a dark accumulation of DAB reaction products in the vascular endothelial cells in cardiac myxoma, but staining of myxoma cells was rarely observed. D, PCNA staining. A positive reaction for PCNA was observed as a dark accumulation of DAB reaction products in the myxoma cells.

\section{Results}

RT-PCR for VEGF. RT-PCR for VEGF of the 7 myxomas is shown in Fig 1. All of the 7 tumors were positive for VEGF messenger (m) RNA, whereas the 2 atrial septum and 2 atrial tissues were negative.

Immunostaining for VEGF. In cardiac myxoma (Fig 2, A), a positive immunoreaction for VEGF was observed as a dark accumulation of DAB reaction products in the cytoplasm of the tumor cells (Fig 2, B). In all 15 tumors, tumor cells in the myxoma were stained and then scored. Among the myxoma specimens, 4 were scored,++++ 4 were scored,+++ 4 were secored ++ , and 3 were scored + . There were thus 8 in the highVEGF expression group and 7 in the low-VEGF expression group. In the atrial septum and atrial tissues no positive immunoreaction for VEGF was observed.

The relationships between VEGF expression and the clinicopathologic features were then investigated. The mean age of the patients did not differ between the high-VEGF expression group and the low-VEGF expression group $(61.6 \pm 13.4$ years vs $59.7 \pm 20.5$ years; $P=.7$ ), and the mean serum $C$-reactive protein in the patients did not differ between the high-VEGF expression group and the low-VEGF expression group $(1.22 \pm 0.9 \mathrm{mg} / \mathrm{dL}$ vs $1.29 \pm 1.14 \mathrm{mg} / \mathrm{dL} ; P=.9)$. No other variables, including sex of the patients, location, and macroscopic findings of the myxoma, differed significantly between the high-VEGF expression group and the low-VEGF expression group. However, the tumor size of the high-VEGF expression group was smaller than that of the low-VEGF expression group $(49.0 \pm 12.0 \mathrm{~mm}$ vs $66.1 \pm 12.7 \mathrm{~mm} ; P=.02)$.

Measurement of microvessel density. A positive reaction for PECAM-1 was observed as a dark accumulation of DAB reaction products in the vascular endothelial cells in the cardiac myxoma (Fig 2, C). 

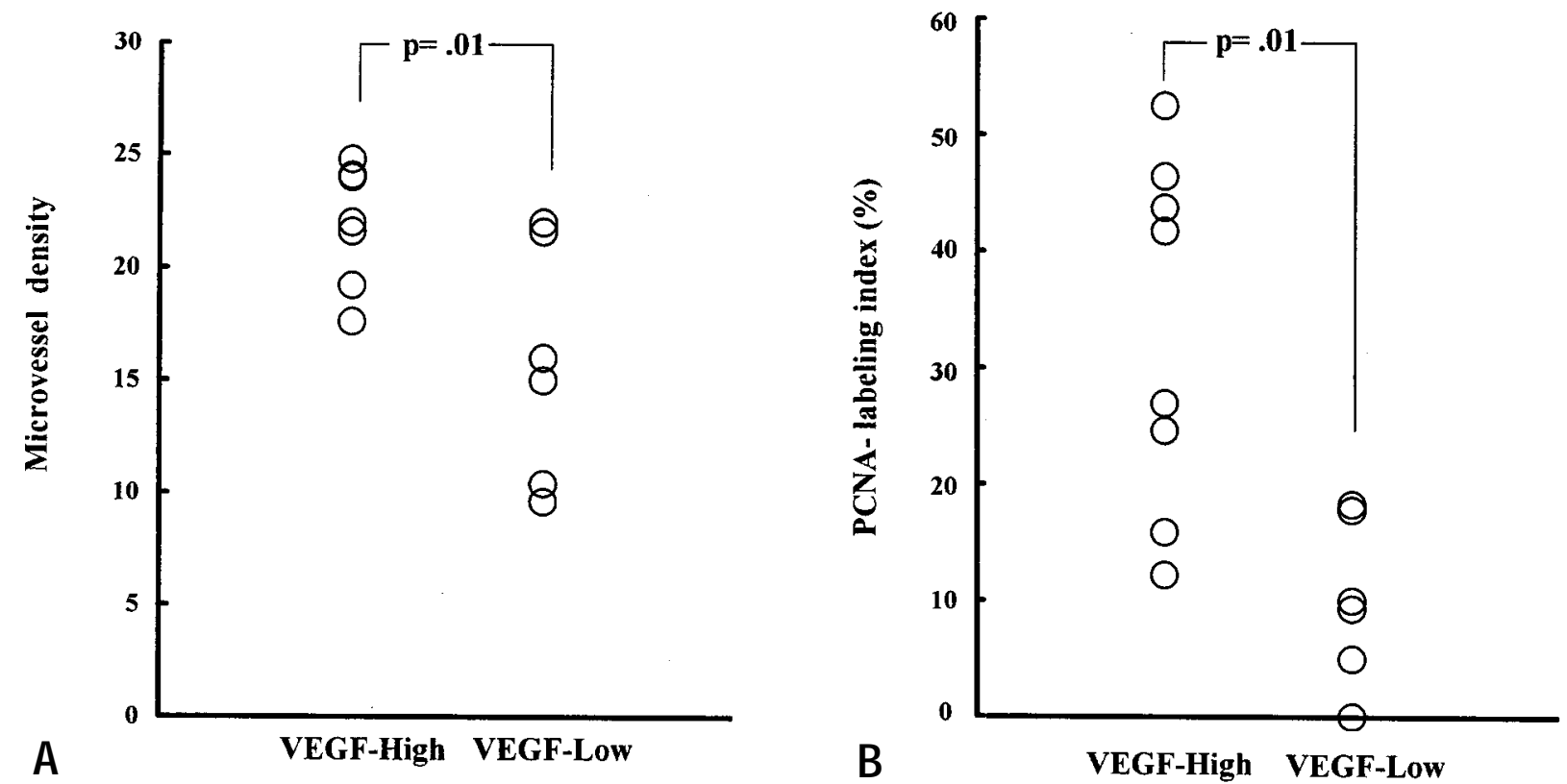

Fig 3. The relationship between VEGF expression and microvessel density or PCNA-labeling index. A, The relationship between microvessel density and VEGF expression in cardiac myxoma showed that the microvessel density in myxomas with high VEGF expression was higher than that in myxomas with low VEGF expression. B, The relationship between PCNA-labeling index and VEGF expression in cardiac myxoma showed that the PCNA-labeling index in the high-VEGF expression group was higher than that in the low-VEGF expression group.

Myxoma cells were occasionally stained for PECAM1. Blood vessels were judged as circle formations of endothelial cells stained by PECAM-1 immunostaining and frequently included red blood cells. Under microscopic observation, in large myxomas microvessels were more frequently observed in the peripheral part than in the central part of the tumors. The microvessel density varied from 9.6 to 24.8 (18.8 \pm 5.4 , means \pm $\mathrm{SD})$, and the ratio of the microvessel density in the central part to the microvessel density in the peripheral part varied from 0.54 to $1.40(0.91 \pm 0.31)$. There were no significant correlations between microvessel density and any of the clinicopathologic features.

Regarding the relationship between the microvessel density and VEGF expression in cardiac myxoma, the microvessel density in the high-VEGF expression group was higher than that in the low-VEGF expression group (22.2 \pm 2.6 vs $15.0 \pm 5.2 ; P=.01 ;$ Fig $3, A)$. The relationship between microvessel density and the tumor size was then investigated. There was a weak but nonsignificant correlation between the tumor size and microvessel density $(r=-0.29 ; P=.3$; Fig $4, A)$. There was a significant inverse correlation between the tumor size and the ratio of the microvessel density in the cen- tral part to the microvessel density in the peripheral part $(r=-0.53, P=.04$; Fig $4, B)$.

Measurement of the PCNA-labeling index. A positive reaction for PCNA was observed in nuclei, which was characterized as a dark accumulation of DAB reaction products. PCNA-positive myxoma cells were distributed at random in the myxoma tissue (Fig 2,D). The PCNA-labeling index varied from $0 \%$ to $52.5 \%$ $(21.6 \% \pm 17.2 \%$, mean \pm SD) in the 15 myxomas. The PCNA-labeling index in the high-VEGF expression group was higher than that in the low-VEGF expression group $(33.0 \% \pm 15.0 \%$ vs $8.6 \% \pm 7.6 \% ; P=.01$; Fig $3, B)$. In addition, there was a weak correlation between the PCNA-labeling index and microvessel density $(r=0.50 ; P=.06 ;$ Fig $5, A)$. Furthermore, there was an inverse correlation between the PCNA-labeling index and the tumor size $(r=-0.66, P=.01$; Fig $5, B)$.

\section{Discussion}

Many studies have shown that tumors depend on angiogenesis for their growth and metastasis. ${ }^{3}$ It is generally assumed that microvessel formation in or around the tumor is stimulated by angiogenic factors, ${ }^{4}$ such as VEGF secreted by tumor cells. VEGF plays an impor- 


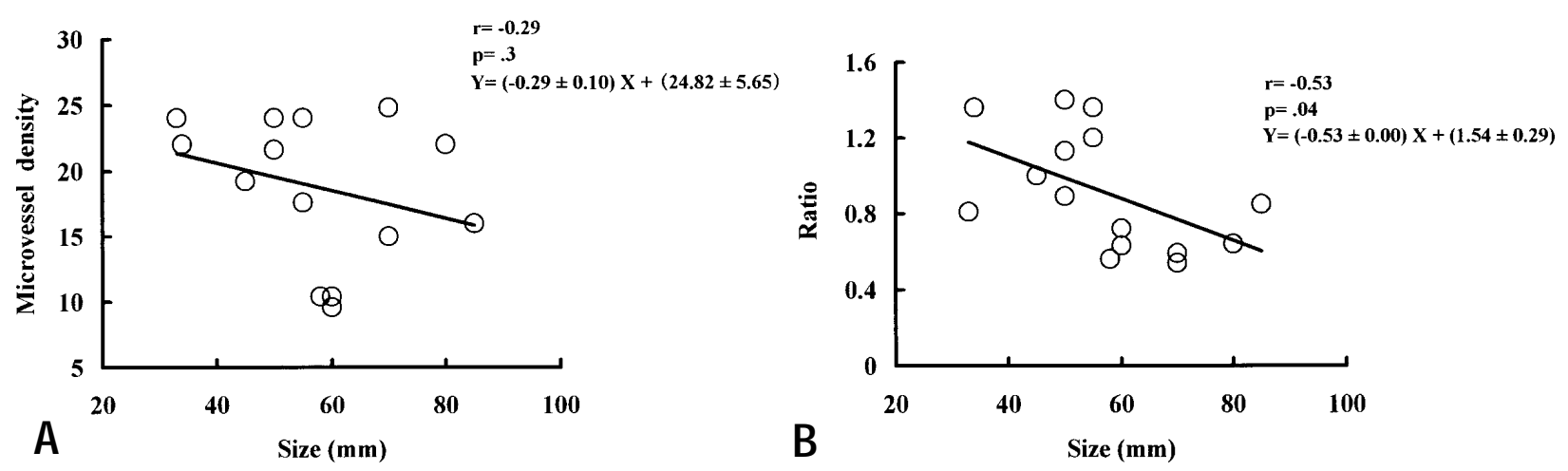

Fig 4. The relationship between microvessel density and tumor size. A, There was a weak correlation between the microvessel density and tumor size. B, There was an inverse correlation between the ratio of the microvessel density in the central part to the microvessel density in the peripheral part of the cardiac myxoma and tumor size.
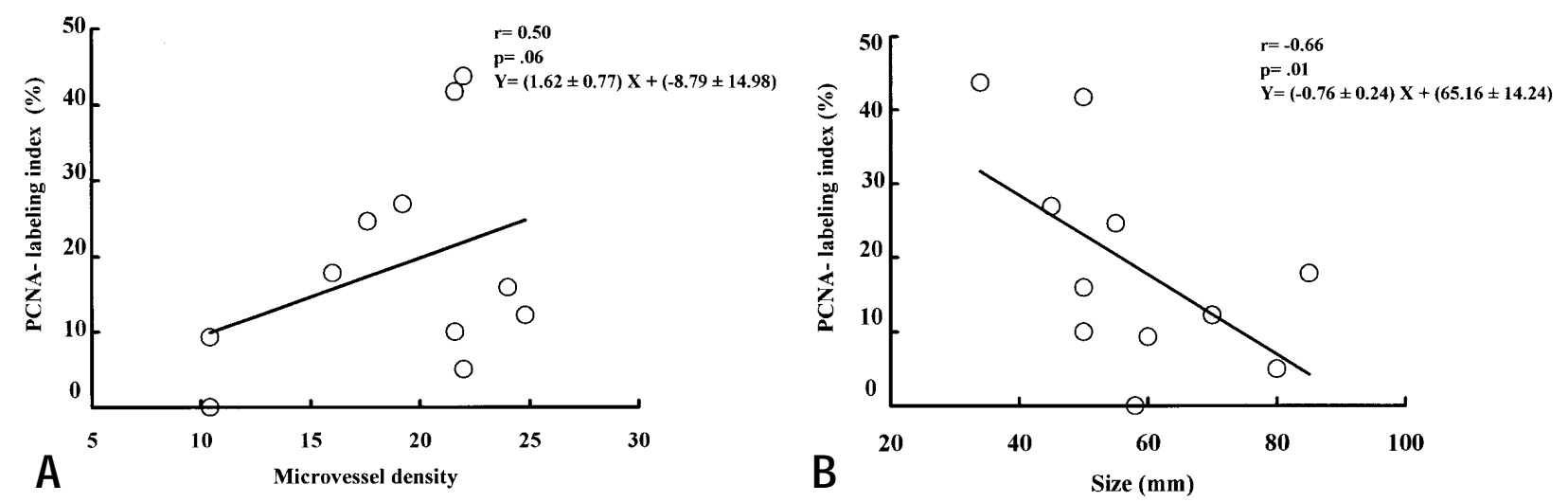

Fig 5. The relationship between PCNA-labeling index and microvessel density or tumor size. A, There was a weak correlation between PCNA-labeling index and microvessel density. B, There was an inverse correlation between PCNA-labeling index and tumor size.

tant role in angiogenesis by increasing the permeability of microvessels ${ }^{12}$ and by stimulating the selective mitosis of vascular endothelial cells. ${ }^{6,13}$ We analyzed the gene expression of VEGF in cardiac myxoma. All of the resected myxomas were positive for VEGF mRNA, whereas atrial tissues were negative for VEGF mRNA. In the immunohistochemical analysis a positive reaction for VEGF was observed in myxoma cells of all the resected patients. Previous studies have shown that VEGF expression was markedly increased in tumor cells compared with adjacent normal tissues in several types of tumors, such as those found in breast cancer. ${ }^{14,15}$ In this study a similar result was found in cardiac myxomas. Therefore in cardiac myxoma it is considered that VEGF is mainly expressed in the myxoma cells.

A significant correlation between microvessel densi- ty and VEGF expression has been reported in clinical specimens of several tumors. ${ }^{16,17}$ Similarly, in this study microvessel density in the high-VEGF expression group was higher than that in the low-VEGF expression group. Therefore the fact that cardiac myxoma with high expression of VEGF showed a high density of vascularity may indicate that VEGF plays a key role in angiogenesis for this tumor. In malignant tumors the tumor cells produce several angiogenic factors, and these angiogenic factors induce neovascularization, which then enhances tumor growth. This concept is known as the autocrine effect of angiogenic factors for tumor cells. It is hypothesized that cardiac myxoma may have such an autocrine system regulating angiogenesis and tumor growth.

Concerning clinicopathologic features, in malignant tumors, including those found in breast ${ }^{14}$ and gastroin- 
testinal cancers, ${ }^{15}$ it is reported that VEGF expression and microvessel density are correlated with the growth in size and clinical aggressiveness of the tumors. With regard to the tumor size of cardiac myxoma, the size in the high-VEGF expression group was smaller than that in the low-VEGF expression group, and microvessel density in large tumors was relatively lower than that in small tumors. Furthermore, in large tumors microvessels were frequently observed in the peripheral part compared with the central part of the myxoma. Therefore in cardiac myxoma it is speculated that angiogenesis frequently occurs in the central part of the tumor in the early stages of tumor growth, whereas it frequently occurs in the peripheral part of the tumor as it grows larger. In addition, it is speculated that abundant vascular supply in the peripheral part of the tumor is necessary for its growth. Although angiogenesis is important for the growth of cardiac myxoma, the role of angiogenesis in cardiac myxoma may be different from that in malignant tumors. The specific growth conditions of myxomas in the cardiac chamber may affect their angiogenesis.

PCNA has been recognized as an auxiliary protein for DNA polymerase-delta and as an endogenous histologic marker for the late G1/S phase in the cell cycle ${ }^{18}$ and therefore has been used for investigating cell proliferation in solid tumors. ${ }^{19}$ To clarify the association between angiogenesis and cell proliferation in cardiac myxoma, relationships between VEGF expression and PCNAlabeling index or microvessel density and PCNA-labeling index were additionally investigated. The PCNAlabeling index was high in small myxomas with both high microvessel density and high VEGF expression. Namely, small cardiac myxomas in the early stage of tumor growth may show high proliferative activity, and angiogenesis induced by VEGF (probably secreted by myxoma cells) may be needed for the tumor growth.

In conclusion, cardiac myxomas produce VEGF, which probably contributes to inducing angiogenesis for the tumor growth, especially in the early stage.

We thank Professor S. Murase for his assistance with statistical analysis.

\section{REFERENCES}

1. Lie JT. The identity and histogenesis of cardiac myxoma. A controversy put to rest. Arch Pathol Lab Med 1989;113:724-6.

2. Malekzadeh S, Roberts WC. Growth rate of left atrial myxoma. Am J Cardiol 1989;64:1075-6.
3. Folkman J. What is the evidence that tumors are angiogenesis dependent? J Natl Cancer Inst 1990;82:4-6.

4. Folkman J, Shing Y. Angiogenesis. J Biol Chem 1992;267:109314.

5. Ferrara N, Henzel WJ. Pituitary follicular cells secrete a novel heparin-binding growth factor specific for vascular endothelial cells. Biochem Biophys Res Commun 1989;161:851-8.

6. Gospodarowicz D, Abraham JA, Schilling J. Isolation and characterization of a vascular endothelial cell mitogen produced by pituitary-derived folliculo stellate cells. Proc Natl Acad Sci USA 1989;86:7311-5.

7. Fueredi GA, Knechtges TE, Czarnecki DJ. Coronary angiography in atrial myxoma: findings in nine cases. Am J Roentgenol 1989;152:737-8

8. Parums DV, Cordell JL, Micklem K, Heryet AR, Gatter KC, Mason DY. JC70: a new monoclonal antibody that detects vascular endothelium associated antigen on routinely processed tissue sections. J Clin Pathol 1990;43:752-7.

9. Burke AP, Virmani R. Cardiac myxoma a clinicopathologic study. Am J Clin Pathol 1993;100:671-80.

10. Chomczynski P, Sacchi N. Single-step method of RNA isolation by acid guanidinium thiocyanate-phenol-chloroform extraction. Anal Biochem 1987;162:156-9.

11. Maeda K, Chung Y, Takatsuka S, Ogawa Y, Sawada T, Yamashita $\mathrm{Y}$, et al. Tumor angiogenesis as a predictor of recurrence in gastric carcinoma. J Clin Oncol 1995;13:477-81.

12. Senger DR, Connolly DT, Water LVD, Feder J, Dvorak HF. Purification and $\mathrm{NH}_{2}$-terminal amino acid sequence of guinea pig tumor-secreted vascular permeability factor. Cancer Res 1990; 50:1774-8.

13. Connolly DT, Heuvelman DM, Nelson R, Olander JV, Eppley BL, Delfino JJ, et al. Tumor vascular permeability factor stimulates endothelial cell growth and angiogenesis. J Clin Invest 1989;84:1470-8.

14. Yoshiji H, Gomez DE, Shibuya M, Thorgeirsson UP. Expression of vascular endothelial growth factor, its receptor, and other angiogenic factors in human breast cancer. Cancer Res 1996;56:2013-6.

15. Maeda K, Chung Y, Ogawa Y, Takatsuka S, Kang S, Ogawa M, et al. Prognostic value of vascular endothelial growth factor expression in gastric carcinoma. Cancer 1996;77:858-63.

16. Takahashi Y, Kitadai Y, Bucana CD, Cleary KR, Ellis LM. Expression of vascular endothelial growth factor and its receptor, KDR, correlates with vascularity, metastasis, and proliferation of human colon cancer. Cancer Res 1995;55:3964-8.

17. Takahashi Y, Cleary KR, Mai M, Kitadai Y, Bucana CD, Ellis LM. Significance of vessel count and vascular endothelial growth factor and its receptor (KDR) in intestinal-type gastric cancer. Clin Cancer Res 1996;2:1679-84.

18. Bravo R, Frank R, Blundell PA, Macdonald-Bravo $H$. Cyclin/PCNA is the auxiliary protein DNA polymerase-delta. Nature 1987;326:515-7.

19. Robbins BA, de la Vega D, Ogata K, Tan EM, Nakamura RM. Immunohistochemical detection of proliferating cell nuclear antigen in solid human malignancies. Arch Pathol Lab Med 1987; 111:841-5. 